\title{
SOCIAL SUPPORT RESOURCE OUTCOMES FOR THE CLIENTS OF TWO ASSERTIVE COMMUNITY TREATMENT TEAMS
}

\author{
Joseph Walsh, Ph.D., L.I.S.W. \\ The Ohio State University, 1992 \\ Coordinator of Community Treatment Services \\ North Community Counseling Centers \\ 4897 Karl Road \\ Columbus, Ohio 43229
}

This research was funded by the Ohio Department of Mental Health, Office of Program Evaluation and Research,

Grant No. 92.1049 
In the practice-based profession of Social Work, case management is defined as an approach to service delivery. which attempts to ensure that clients with multiple problems and disabilities receive all the services they need in a timely, appropriate fashion (Rubin, 1987). With the passage of the Mental Health Act of 1988, community-based case management services have become the preferred treatment modalities in Ohio for working with severely mentally disabled (SMD) clients at public mental health agencies. This is in fact a national trend, reflecting the commitments of state mental health policy makers to the aggressive promotion of rehabilitative alternatives to custodial care. SMD clients, including those with schizophrenia and other chronic psychotic disorders, tend to have poor social and vocational skills and require much assistance in meeting their basic material and emotional needs. Yet, it is speculated that SMD clients can only achieve functional independence to the extent that they can develop natural social supports in the community to augment the supportive roles of social workers and other mental health professionals.

Social supports, which are by definition external to the individual, promote improved physical health, mental health, stress-coping capability, and community integration (Vaux, 1988). A key task for the case manager in assisting SMD clients with the adjustment to community living should involve the cultivation of social support resources toward those ends. The problem of concern to this researcher is that while a variety of case management programs have been implemented in mental health agencies, their impact on natural support resource development has received little scrutiny. Further, there is a need for types of community-based programs to be compared to one another with regard to social support or any other outcomes in order to determine relative effectiveness. Assertive case management programs have most often been compared in outcome research to traditional or office-based interventions.

\section{Research Background}

The social supports of SMD persons are relatively meager. Cutler, Tatum, and Shore (1987), in a study of two community support programs, estimated their social networks as consisting of ten to thirteen others in only one or two clusters (persons with whom one interacts in a particular role or activity). Atkinson (1986) documented an average network size of 13 persons in three clusters for SMD clients in an English community. This is in contrast to studies of general populations, which tend to report network sizes of 22 to 25 others, including five or six persons in clusters comprised of work associates, nuclear family, extended family, neighbors, and friends (Greenblatt, Becerra, \& Serafetinides, 1982). Cutler and Tatum (1983) characterized SMD persons as living in small networks, having high levels of ambivalent relationships with relatives, and having few cluster contacts and long-term relationships outside the family.

Because assertive community-based case management for SMD persons is a relatively recent phenomenon, research on its effectiveness in achieving various outcomes dates back only to the late 1970s. Solomon (1992) reviewed twenty studies on case management effectiveness, fourteen of which involved "full support" team models similar to those studied by the present author. Case management was generally found to be more effective than other interventions, but system outcomes such as reduced cost and hospitalizations were more frequently observed than clinical outcomes, including symptomatology and quality of life. Studies of case management effectiveness have not focused on social support as a variable of primary concam. 
Several conclusions can be drawn from the above discussion. First of all, the dependent variable of social support is either absent or a minor consideration thus far in the literature. There seems to be a lack of appreciation for the importance of natural social support system building with SMD clients as an outcome of intervention. Secondly, while there have been comparisons of assertive community-based and traditional aftercare interventions, there has been no research conducted on the relative effectiveness of group and individual based community treatment approaches with regard to any outcomes. The objective of this study was to determine which of two types of case management intervention better facilitated the development of natural supports for SMD clients.

\section{The Hypotheses}

Four research hypotheses were investigated, three of them directional, as listed below. Each was tested at an .05 level of significance.

1. Severely mentally disabled clients participating in the group-treatment oriented community treatment team (CTT) program will report interactions in more social network clusters than clients participating in the individual-treatment oriented CTT program.

2. Severely mentally disabled clients participating in the group-treatment oriented CTT program will report larger personal networks than clients participating in the individual-treatment oriented CTT program.

3. Severely mentally disabled clients participating in the group-treatment oriented CTT program will report a greater level of perceived support from friends than clients participating in the individual-treatment oriented CTT program.

4. There is a difference in the perceived levels of social support from family members between SMD clients of the two community treatment teams.

\section{Methodology}

This research has investigated through quantitative methods and an ex post facto design a comparison of the social support resources developed by the SMD clients of two types of community treatment teams in Franklin County. Social support is defined as the social interactions and relationships that provide individuals with actual assistance or feelings of attachment to other persons perceived as caring (Hobfoll, Freedy, Lane, and Geller, 1990). A related concept, that of the social network, refers to a person's patterns of interaction which emerge as a result of exchanging resources with others with sufficient magnitude that a commitment to the relationship develops (Specht, 1986). The personal or support network is a subset of the social network, and includes those whom an individual sees regularly and identifies as important in his or her life (Moxley, 1988). Network clusters were defined earlier. In this project, eleven network clusters were studied including the family of origin, extended family, family of procreation, work or volunteer contacts, neighbors, informal community relations, church or religious activity contacts, associations, recreational contacts, school contacts, and the residual category of "others".

The independent variable in this study was type of case management intervention, and included the two levels of group-based and individual-based treatment. Two teams from different but demographically similar community mental health centers were selected for study from among 23 teams representing an innovative SMD treatment program operating in the 
Franklin County, Ohio community mental health system. Throughout the county, case managers in five-member teams were providing rehabilitation services to clients almost entirely in their natural environments. Of the teams selected for inclusion in this study, one provided services largely in group settings, while the other assigned case managers to work with clients individually. The group-based treatment team (Team G) conducted six socialization groups of 2.5 hours duration each week, with $60 \%$ of its caseload attending at least two groups weekly and $75 \%$ attending at least one group monthly. The individual-treatment oriented team (Team I) conducted only one group outing every few months, and reported an attendance rate of approximately $20 \%$ at these events. The teams shared a similar philosophy of care as determined by Jerrell and Hargreaves' (1988) Community Support Philosophy Scales.

Analysis of covariance methods were utilized to measure four components of social support as dependent variables, including social network cluster involvements, personal network size, and levels of perceived social support from friends and family. These dependent variables were derived from theoretical formulations in the literature regarding the support needs of the SMD population relative to community tenure. Five control variables were drawn from the literature to statistically equalize the two intact groups of treatment team clients on relevant dimensions. Levels of these covariates are all associated with support resource acquisition and include gender (House, Umberson, and Landis, 1988), race (Coates, 1990), diagnosis (Beels, 1981), duration of program participation (Bond, Miller, Krumweid, and Ward, 1988), and degree of functional impairment (Denoff and Pilkovis, 1987).

Data was collected using two existing instruments, developed by Moxley (1988) and Procidano and Heller (1983), which had been previously tested for reliability and validity with SMD populations. The Moxley instrument provides information about a respondent's network size and composition, and differentiates between the overall social network, the personal or support network, and cluster sizes. The Procidano and Heller questionnaire derives subjective ratings of the supportiveness of friends and family. The treatment team case managers, blind to the objectives of the study, collected all data as a means of further enhancing the validity of responses from the psychiatrically impaired samples. One hundred twenty-five (125) respondents were interviewed (64 from one team and 61 from the other), which included over $80 \%$ of the clients from each team.

\section{Results}

There was a significant difference between treatment groups in social support resources with regard to the personal network size. That is, SMD clients of Team $G$ had developed larger personal networks than the clients of Team I (10.71 vs. 7.10). While the client samples were not different with regard to the other three measures of social support, personal network size has been previously documented as predicting overall social integration (including numbers of informal contacts and community resource use) more fully than the other dependent measures.

There were also significant differences between the samples in the sizes of several social and personal network clusters. The Team $G$ sample reported a larger social network recreational cluster size (1.99 vs .54), as well as more contacts in the personal network work or volunteer (1.0 vs .75), associations (.78 vs .23), and recreational (1.11 vs .19) clusters. All of these cluster involvements require the application of social skills, and the work or volunteer and associations clusters involve interactions with "normal". persons in the community. Group-based team treatment thus seems to promote social support rescurce development within neiworks by 
enhancing the development of clients' overall social skills which can be generalized to other social settings.

Covariance effects were noted with a number of dependent variables, but most striking was the effect of gender on social support network size. The main effect of gender on personal network size, and the interaction of gender with type of treatment on both social and personal network size, indicates that males in group-based treatment developed more network members than females. This is contrary to what is reported in much of the literature, which is that women tend to be more effective than men at both giving and receiving support. Perhaps SMD women, like women in general populations, seek support through intimacy rather than taskoriented activity and experience a similar amount of support with fewer contacts (Heller, Price, and Hogg, 1990).

\section{Utility for Social Work Practice}

This pilot study supports the strategy of utilizing group activities in assertive community treatment interventions as a means of enhancing informal social supports for SMD clients. While Team $G$ was non-specific in its goals for social support development, its approach was nonetheless consistent with that outlined by Gottlieb (1992), who suggested that attempting to match types of supportive activity to specific client needs oversimplifies the complex process of support receipt. The long-term support group approach to intervention enables clients to gradually select their own supportive relationships characterized by reciprocity, and subsequently improve their social skills. The group-oriented program was based on this strategy. Its clients had developed larger personal networks and also maintained larger numbers of contacts in four clusters which demanded the application of social skills.

It is not this researcher's intent, however, to deemphasize the importance of individual case manager/client interactions in any type of assertive community treatment. Much rehabilitative work with SMD clients must be done on a one-to-one basis, and the Team G social workers routinely included such interventions in their work. The social worker's relationships with his or her clients is crucial to the success of all interventions, and has the same therapeutic components as any other clinical relationship (Kanter, 1989). Particular attention needs to be given to the relationship-based support needs of women. Task-oriented group tend to more readily meet the needs of men. Social workers might build the support of SMD women more effectively by engaging them in small groups focused on a variety of women's issues.

The lack of sample difference in perceptions of support may indicate a special problem among SMD clients. It is possible that their social isolation, related to marginal social status and the chronicity of severe mental disorders, results in an affective indifference to the presence of more or less support. This issue has been addressed by Sullivan and Poertner (1989) as a problem in social support intervention with SMD clients. The perception of support may not correlate as well with the experience of being supported in the SMD population as it does in more general populations. Vaux (1988) has pointed out that few instruments utilize episodes of past or present supportive behaviors as indicators of social support, probably due to measurement problems. However, such a strategy may be useful in further studies of social support with the SMD population. 


\section{REFERENCES}

Atkinson, D. (1986). Engaging competent others: A study of the support networks of people with mental handicap. British Journal of Social Work, 16, 83-101.

Beels, C. (1981). Social networks and the treatment of schizophrenia. International Journal of Family Therapy, Winter, 310-315.

Bond, G., Miller, L., Krumweid, R. \& Ward, R. (1988). Assertive case management in three CMHCs: A controlled study. Hospital and Community Psychiatry, 39, 411-418.

Coates, D. (1990). Social network analysis as mental health intervention with African-American adolescents. In Serafica, F., Schwebel, A., Russell, R., Isaac, P. \& Myers, L. (Eds.), Mental health of ethnic minorities (5-37). New York: Praeger.

Cutler, D. \& Tatum, E. (1983). Networks and the chronic patient. In Cutler, D. (Ed.), Effective aftercare for the 1980s (13-22). New Directions for Mental Health Services, San Francisco: Jossey-Bass.

Cutler, D., Tatum, E. \& Shore, J. (1987). A comparison of schizophrenic patients in different community support treatment approaches. Community Mental Health Journal, 23, 103113.

Denoff, M. \& Pilkovis, P. (1987). The social network of the schizophrenic: Patient and residential determinants. Journal of Community Psychology, 15, 228-244.

Gottlieb, B. (1992). Quandries in translating support concepts to intervention. In Viel, H. \& Baumann, U. (Eds.), The Meaning and Measurement of Social Support (293-309). New York: Hemisphere Publishing Co.

Greenblatt, M., Becerra, R. \& Serafetinides, E. (1982). Social networks and mental health: An overview. American Journal of Psychiatry, 139, 977-984.

Hammer, M. (1981). Social supports, social networks, and schizophrenia. Schizophrenia Bulletin, 7, 45-57.

Heller, K., Price, R. \& Hogg, J. (1990). The role of social support in community and clinical interventions. In Sarason, b., Sarason, I. \& Pierce, G. (Eds.), Social support: An interactional view (482-507). New York: Wiley and Sons.

Hobfoll, S., Freedy, R., Lane, C. \& Geller, P. (1990). Conservation of social resources: Social support resource theory. Journal of Social and Personal.Relationships, 7, 465-478. 
House, J., Umberson, D. \& Landis, K. (1988). Structures and processes of social support. American Review of Sociology, 14, 293-318.

Jerrell, J. \& Hargreaves, W. (1991). The operating philosophy of community programs (Working paper series 18). Berkeley, California: Institute for Mental Health Services Research.

Kanter, J. (1989). Clinical case management: Definition, principles, components. Hospital and Community Psychiatry, 40, 361-368.

Moxley, D. (1988). Measuring the social support networks of persons with psychiatric disabilities: A pilot investigation. Psychosocial Rehabilitation Joumal, 11, 19-28.

Procidano, M. \& Heller, K. (1983). Measures of perceived social support from friends and family: Three validation studies. American Journal of Community Psychology, 11, 124.

Rubin, A. (1987). Case management. Encyclopedia of social work (212-222). Silver Spring, Maryland: National Association of Social Workers.

Solomon, P. (1992). The efficacy of case management services for severely mentally disabled clients. Community Mental Health Journal, 28, 163-180.

Specht, H. (1986). Social support, social networks, social exchange, and social work practice. Social Service Review, June, 218-240.

Sullivan, W. \& Poertner, J. (1989). Social support and life stress: A mental health consumers perspective. Community Mental Health Journal. 25, 21-32.

Vaux, A. (1988). Social support: Theory, research, and intervention. New York: Praeger. 